\title{
REFLECTIONS ON THE VERGE OF THE TWENTY-FIRST CENTURY*
}

\author{
Prof. Dr. Ersin ONULduRaN**
}

The famous American writer and poet E.E.Cummings, who was a Norton-Harjes ambulance driver in France during World War I, said once that the future struggle for mankind "would be between the world of the born and the world of the made". I thought that he summed up in a few clever words the dilemma our civilized and technologically advanced world of the 1990's faces. Indeed, while we enjoy the fruits of science and technology, we are faced with the problem of endangered species; we are crowded into burgeoning cities encircled by polluted waters and air; and we look for a remedy for the ills that we have brought upon ourselves, especially within the second half of the twentieth century.

All is not bad and hopeless, of course. Let us for a moment take our front row seats and look at what might happen on the world stage in the near future, within our own lifetimes:

Political life. Domestic, but especially international political life, will go through a significant transformation within the next 10 years. Who could have imagined even as late as early 1989 that the massive and formidable Berlin Wall would come down so quickly and completely that, today, except for the few segments saved at the Check Point Charlie Museum and a few other places, there is not even a trace of that forbidding and chilling structure. The Cold War is over, there is now talk of having some of the former Soviet Bloc countries joining NATO and even making the Russian Federation a cooperating state. The former Sovict empire is now gone, but within the next decade I predict that there will be a strong organization formed to incorporate into some sort of a loose confederation, the former Soviet Republics in Central Asia and the Caucasus. In Europe, the European Union will make progress towards a more perfect union, and we will see this organizational example repeated regionally elsewhere in the world such as in Southeast Asia and in North and South America. The United Nations will be reformed to

\footnotetext{
*Dedicated to the memory of Oral Sander who shared a love for technological advances with me.

** A.U. Siyasal Bilgiler Fakütesi, Ogrretim Uyesi.
} 
include for example Germany and Japan in the Security Council, but its political effectiveness in Peace Keeping or Peace Making will still bu: limited by the extent of the political will of its member states. The utility of the United Nations as a forum for almost all aspects of intemational life guarantees its continued existence. Because of this alone, I see it existing well beyond the first decade of the 21 st Century.

On the domestic front, my guess is that a grcater improvement for representative government will take place. Human rights will bo paid grearer respect and the repressive regimes of today will be things of the past. The information revolution will not allow their existence for long. Will there be "A clash of Civilizations" as Professor Samuel Huntington predicts in the $21 \mathrm{st}$ century? I don't think so. While regional wars and terrorism will be with us in the next decade or so, large s.cale wars of the early 20th century will be things of the past. I base this guess on the assumption that as nations get richer and therefore have more and more to lose, they will be reluctant to take part in all-out wars which would cause unbearable damage to their c:onomies and populations.

Economic Life: The world economy has been growing at a healthy pace since the Industrial Revolution. There have been some periods of reversals, most significantly during the five year period immediately following the Greal: Wall Street Crash of 1929. However, partly spurred by the various large and small waris, the industries of the richer nations have shown remarkable advances in the service of ntankind. Today an ordinary car is more affordable for the middle classes than the Model A was in Henry Ford's time.

Electronic and optical goods and household appliances are actually cheaper now than they were 10 years ago when measured agrainst a family's income in the Western Industrialized nations. The gap between the rich and the poor, however, has widened, both on an individual and national basis. I think that in the next decade this gap will close somewhat and the lot of the marginal nxasses living in poorcr nations will be impioved greatly.

A case in point is South Korea, this nation through hard work and some outside help, was able to increase its industrial output fifty fold and its exports one hundred fold during the twenty year period from the mid 196''s to the mid 1980's. On the verge of the 21 st century it is even in better shape than ten yesurs ago. Taiwan, Hong Kong, Malaysia and Singapore are all more or less in the same situation. I predict that both China and the "Largest Democracy in the World", India will emerge as economic giants. The sectarian violence in India will diminish, China will ix measurably more liberalized politically, and neither will suffer a bloody revolution.

Using cash in daily transactions will be even less common than it is today and purchases made through home computers and Internet venclors will not rate a mention even in daily conversations. Already, several large automobile dealers in the United States have gone the way of online car sales and reduced to nil the considerable anxiety of buying a new car from car lots and haggling for the best price. I think banking will be done almost exclusively from the homes and through the: use of touch-tone telephones and ATM machines. This will increase the number of large national banks in the United States, thus making American banks catch up with their counterparts in large nations elsewhere. 
Globalization on the economic front will make considerable headway, and world economies will be intertwined which will in turn provide for greater freedom in the flow of goods and services across national borders. The result of this will be the disappearance of tariff barriers and a keen world-wide competition among industrial complexes resulting in the survival of the fittest.

Education and Culture. This is the area where I think the greatest care has to be taken in considering what tomorrow will bring. Already there are complaints that the information bombardments of the 1990's is not resulting in the increase of "knowledge" at the pace one would have expected. While it is the job of the epistemologists to argue about the philosophy of knowledge and whether information and knowledge will lead us to "truth", we have to be very careful that cultural values nurtured over centuries in a given country are not sacrificed to the expediencies of digital images or sounds. In fact, I don't think this is as imminent a danger as doomsday sages would have us believe.

I think in the first years of the next millennium we will see an increased rate of literacy and computer literacy even among the less fortunate groups of human society. In my own life time the literacy and illiteracy rates in my own country have been completely reversed. When I was born, right after the Second World War, the rate of literacy in Turkey was about 25 per cent. Now the rate of illiteracy is well below this figure.

The preservation of distinct cultural values is more tricky. On the one hand we want globalization and even the attainment of "a global village" as predicted by the Canadian Communications Guru Marshall McLuhan 32 years ago, where mass communications will have brought people and feelings together into a caring village environment. On the other hand, the total replacement of cultural values by other, foreign ones must be resisted. Indigenous cultures will be enriched by being adorned with adaptations from other cultures, but cultural replacement will be considered unwelcome by most, well into the 21 st Century.

The World of the Born. I am using this term to refer to all living organisms. From the lowly amoebae to that wonder of complexity, the human being, the world of the born will see many changes and face many questions in the 21st century. The very delicate balance of ecology will have to be jealously guarded.

Let me illustrate this point with a true story. Approximately 4 years ago a cargo ship took on its load from somewhere on the Atlantic coast of North America. Perhaps because the ship was not heavy enough, or perhaps the because the captain thought a little more weight would make for a smoother ride, it took on several tons of sea water into its holds at the beginning of the journey. After about three weeks at sea and a relatively uneventful trip, our ship arrived at its destination on the northern shores of the Black Sea, unloaded its cargo, and pumped out the excess sea water it had taken on for ballast. In the spring of 1993, a Russian oceanographic trawler which was on a routine sample collection mission found a five centimeter long jelly fish which was not indigenous to these waters among its newly collected samples. This jellyfish was a native of the North Atlantic. In 1995 the new jellyfish population in the Black Sea was estimated to have grown to several thousand cubic tons. As luck would have it, this kind of jelly fish ate the same plankton that baby anchovy fish eat in the Black Sea. Anchovy 
was very plentiful and a main staple of the people living in a!l the countries surrounding the northeastern Black Sca area. Because of this shortness of food supply, the anchovy harvest in the Turkish Black Sea coasts and most probably clsewhere in the region has fallen to one third of its previous levels. The people are suffering shortages of this kind of food, and the economies of the region are in distress because of the shortage of the fish.

This story goes to show how careful we must be about introducing species not indigenous to a given area and to keep the ecological balance we have. In this vein I greeted with great personal alarm the news last summer that some Martian rocks had been found to contain certain fossilized remnants of life forms which may have existed on that planet. An invasion of an alien microbe from outer space could cause incalculable devastation on earth. This is not some science fiction story, this could be a very real danger with increased exposure to outer space that we will surely see in the 21 st century.

As we talk about the "world of the born", we must not neglect certain medical and ethical questions concerning the "as yet unborn." I ar. referring to the problems we are facing even now with surrogate motherhood, whereby an embryo is placed in the womb of a woman who bears it to term, gives birth to the child and turns it over to the couple with whom she had made an agreement. As we all lnow, some women do this for altruistic reasons and some for money. Hosting a child in this fashion may have later implications that armies of lawyers, doctors and clergymen vill have to deal with in the near future as these events increase in frequency, bringing with them the possibility of controversy and contention. Along similar lines. some controversy has already cropped up about bearing a new child into a family in order to save, the life of a sibling suffering from leukemia or some form of autoimmune system disease. This is done in order to harvest some of the precious bone marrow of the new child to be used to give life to the sick brother or sister. While I personally do not see anything; terribly wrong with this, I can appreciate the cthical questions that must be faced in the near future on this subject as well.

The last point I want to raise in man-millieu relationships is the destruction of the Brazilian and other rain forests and the enomous crosion problem we see in the dryer parts of the Northern Hemisphere.

We now know that the rain forests probably hold the key to making new medicines and finding cures to the dread diseases of the current day. On the one hand, the consciousness of the environmentalists is increasing on how valuable an asset these rain forests are and on the other, the pressure of increased population in these areas, the appetite for paper products and timber and rapid econcmic return from logging are increasingly becoming problematic. The land erosion due to deforestation and over use of farmlands is gaining mammoth proportions. For example, in Turkey, a country of moderate size and temperate climate, every year we lose a land mass the equivalent of the Island of Cyprus to erosion by water and wind. My hope is that in a wiser and more economically comfortable 21 st century, reason will prevail and man's destruction of nature will cease.

World of the made. Whenever such things as communications, artificial intelligence, the information age and so forth are mentioncd, computers inevitably come to mind. I often think about what form the world of say five hundred or a thousand years 
from now will take. The answer is hard to guess. I imagine that some form of direct communication will be possible between man and machine at that time. But for our immediate future, the recent book The Road Ahead by Bill Gates, the software magnate, gives us several clues. The American Vice President Al Gore has been talking about the "Information Superhighway". Everyone who has tried it tells us what a wonderful experience "Surfing the Net" is. In fact, I am sure that almost everyone in this audience has had experience with sending and receiving electronic mail. Bill Gates talks about the road or the highway that is already at our doorstep. This road is made not of crushed stones and asphalt, but of fiber optics. The incredibly smooth and fast transfer of data, coupled with the super fast ISDN modems attached to our terminals will create a world where almost any kind of data or image will be able to be called up and experienced instantaneously. We will be able to afford the "white boards", for example for our schools first, and later for our homes. The white board is something like a very thin and very large TV screen which will hang on a wall. By pushing a few buttons or even writing on it, a teacher will be able to call up say a Renoir painting, magnify it to show detail, and conduct an art lesson without slides or reproductions except for what is produced by the "white board". We will be able to call up video images of almost anything on our home white-boards, see vacation places we might want to go to, talk on real-time with loved ones seeing their pictures and hearing their voices even though they might be thousands of miles away. The amazing thing is that this technology is already here and except for a few refinements and making the necessary infrastructure investments, it is wcll within reach of our own.generation.

Aside from the white board, the "electronic wallet" which will take the place of both money and credit cards and the electronic diaries and databanks many of us now carry will soon become commonplace. Already the "smart cards", which took the place of money, were used in Atlanta during the Olympic Games and in Istanbul during the Habitat II conference this past summer.

Will all this convenience make us into hermits and couch potatoes? I don't think so. Look at how many spectators good and exciting movie productions are drawing into the movic theaters right now, even though most of them become available for personal viewing through video cassettes or video discs soon after their release. What virtual reality can replace the high one gets from breathing in the smell of wild flowers from the spring breeze, swimming in the warm blue oceans or down-hill skiing on a sunny day on high mountain slopes?

Access to information is all good and well but please let us be careful that we don't become the subjects of the T.S. Eliot's lament in the poem "the Rocks" where he says:

Where is the life we have lost in living?

Where is the wisdom we have lost in knowledge?

Where is the knowledge we have lost in information?

Conclusion. I have tried in the last few pages to make you look at our near future through my mind's cyc. All of the things I have talked about are going to be possible only if a global and universal education is provided to our young people. The 
key to success in the twenty-first century is going to be how well- rounded and interculturally one is educated. Cultural and academic exchange programs are going to play a key role in the achievement of this kind of education. W'e fear most what we don't know. By the same token, hate sometimes breeds in murky waters. The bright beacon of learning is going to shed its light on the minds of the yourg and let them see things clearly, and hopefully, in a positive light. In today's world no amount of effort or investment will give a better return than that which is put forth in the field of education. Being a teacher or a professor is not always an easy task. Sometimes there are disappointments and frustrations. People in this field should not give up hope, however. Educators should stay steadfast and robust, for the future generations will rise on their shoulders and reach for the skies. 